Research Article

\title{
Evaluation and Improvement of Major Intersection on Eastern Corridor of Gujranwala, Pakistan using SIDRA
}

\author{
Khawaja Adeel Tariq ${ }^{1 *}$, Hadhi Hassan Khan ${ }^{2}$, Shuja Zaib Afghan ${ }^{3}$ and Arslan Raza ${ }^{4}$
}

${ }^{1}$ Department of Civil Engineering, The University of Faisalabad, Faisalabad, Pakistan; ${ }^{2}$ Pavron consultant, Islamabad, Pakistan; ${ }^{3}$ Department of Civil and Environmental Engineering, University of Technology, Sydney, Australia; ${ }^{4}$ Raza Designers and Builders, Lalamusa, Pakistan.

\begin{abstract}
This research focus on assessing traffic conditions at eastern corridor of Gujranwala, City. The selected intersections are Chan Da Qila, Kangniwala Bypass and Sialkot Bypass. The research is performed to identify the existing and future traffic operations at theses intersections. The selected intersections are mostly used by traffic coming to Gujranwala City or moving towards neighboring cities of Daska and Sialkot. The Gujranwala City is also connected with neighboring cities of Lahore and Gujrat through GT Road. The increase in population and vehicles has resulted in traffic congestion on routine basis. The signalized and unsignalized intersection design and research aid software (SIDRA) was used to analyze selected intersection. Topographic survey is conducted for the intersections. Traffic counts are measured manually on every intersection. The data calculated are then changed into Passenger Car Unit (PCU) by applying equivalency factor as recommended by Urban Unit Punjab (Punjab geometric design manual). For computation of Level of Service (LOS), Delay and Volume/Capacity ratio model is used. It is noticed that Level of Services is very poor at these intersections. The modification including provision of additional lanes, signals and increasing lane width is recommended for the intersections. The analysis results of intersection with proposed modification shows improvement in Level of Service.

Received: September 13, 2020; Accepted: June 15, 2021; Published: June 28, 2021

*Correspondence: Khawaja Adeel Tariq, Department of Civil Engineering, The University of Faisalabad, Faisalabad, Pakistan; Email: khawajaadeel@hotmail.com

Citation: Tariq, K.A., H.H. Khan, S.Z. Afghan and A. Raza. 2021. Evaluation and improvement of major intersection on eastern corridor of Gujranwala, Pakistan using SIDRA. Journal of Engineering and Applied Sciences, 40(1): 1-7.

DOI: https://dx.doi.org/10.17582/journal.jeas/40.1.1.7

Keywords: SIDRA software, Passenger Car Unit (PCU), Level of Service (LOS), Traffic count, Intersections
\end{abstract}

\section{Introduction}

$\mathrm{T}$ he urban centers are facing challenges of development of efficient transportation system. If traffic systems of Pakistan can be made more comfortable and environment friendly, it will add billions of rupees per year to the economy of Pakistan in terms of fuel cost and also in terms of environment protection. The performance of the traffic intersections is governed by the overall traffic flow at the intersection. Therefore, the study of crossing is very significant for the traffic engineers to improve the capacity of intersection especially in urban areas (Candappa et al., 2015). Traffic rotaries are form of intersections control in which road traffic is directed to move beside one path around the traffic island. These rotaries are operating on the principle that all the major clashes like right turn traffic conflicts are converted into minor clashes like merging traffic, weaving traffic, and diverging traffic. Traffic rotaries are the form of at-grade intersections which are prepared for the movement of road traffic such that no through clashes are there. 
Merging, weaving and diverging actions decreases the conflicting activities at the rotary (Mathew and Rao, 2007). Pedestrian and turning traffic also plays an important role in intersection design (Arshi et al., 2018). Factors that affect the normal traffic activities at the side of or on the carriage way can be defined as Side friction factors. Considerable reduction in capacity is observed due to Side friction (Salini and Ashalatha, 2018). Degree of saturation, time delay and queue length of vehicle are the indicators that can be used for qualitative assessment of the intersections (Pilko et al., 2011). Road shoulder, bridge geometry and ride comfort are major factor impacting Level of Service for heavy vehicles (Martin et al., 2017). National Cooperative and Highway Research based on geometric design, traffic control devices and public awareness; has recommended guidelines for un-signalized intersections (Neuman et al., 2003).

Gujranwala city is the fifth largest in terms of population amongst the cities of Pakistan. Gujranwala has been at the forefront of continued expansion, forming this city $7^{\text {th }}$ most-populous metropolitan area which sees considerable traffic movements in each direction due to various demographic and social factors. The City still serves as a major trade-link despite it being in close vicinity to the Lahore and Sialkot. The Gujranwala city is in the export triangle of Pakistan including Gujrat, Sialkot and Gujranwala. Due to an industrial hub, the Gujranwala city contribute a major share in the national trade and exports (Hamid, 2017). The population of Gujranwala has increased to 5.0 million but there is less improvement in road infrastructure (Pakistan Bureau of Statistics, 2017).

Gujranwala is the third largest industrial center of Punjab. It is connected to neighboring cities of Hafizabad, Sheikhupura, Sialkot and Gujrat through metalled roads. The traffic flow in the City is made up of motorized and non-motorized modes of $87 \%$ and 13\% respectively (Transport Planning Unit, 2013). The existing road infrastructure in Gujranwala city follows Hub and Spoke pattern. Gujranwala City also has provision of inter and intra-city traffic through its two outer ring road i.e. eastern and western corridor. The use of public transport system in Gujranwala is relatively less as compared with privately owned vehicles. The traffic entering in Gujranwala from Lahore and Sialkot first passes to Chan Da Qila and Sialkot Bypass intersection, respectively.
The Eastern Corridor under investigation for this study included the following major intersections, covering a distance of 13 kilometers between them: Sialkot Bypass intersection, Kangniwala Bypass intersection and Chan Da Qila intersection (Figure 1). The first intersection of analysis is Sialkot Bypass intersection which is a four-legged un-signalized urban roundabout intersection. It is located on the Sialkot Road forming the entry point of traffic from Sialkot and Lahore. Due to the gateway of the city this intersection is much loaded intersection with all types of traffic. Traffic at peak time is pretty much at halt and long queuing of traffic made this intersection very much important to improve; and to reduce the points of conflicts. The second intersection of analysis is Kangniwala Bypass intersection. It is an uncontrolled three-legged intersection. This intersection connects Sialkot Bypass to the G.T road. This intersection has traffic coming from Sialkot, Pasrur, Lahore and also the traffic coming through the city. It contains mainly all types of traffic. This intersection also contains a disposal road which disposed the traffic to the western route. This intersection is important to study because of lack of U-turn provided for the vehicles coming from Sialkot and also heavy traffic turning to the Sialkot is creating a huge point of conflict creating a blockage of traffic at peak time. The third and last intersection of analysis is Chan Da Qila Intersection. It is an uncontrolled three-legged roundabout intersection. It is also a gateway intersection for the traffic coming from Gujranwala city. This intersection is loaded with all types of traffic. This intersection is improved in past but the problem is still unsolved and roads are congested during peak times (Punjab Development Statistics, 2014). This intersection connects the traffic coming from major cities i.e. Lahore, Gujranwala and Sialkot. The study area of the selected intersections is shown in Figure 2.

The present and future intersection scenarios can be analyzed using Signalized and unsignalized Intersection Design and Research Aid (SIDRA) Software. Improvements due to proposed changes in the geometry of selected intersections are evaluated using SIDRA. It is used worldwide for complex traffic analysis (Sabra et al., 2000). The measure of the value of flow is called level of service (LOS). It is the measure of how well that facility is operational. The level of service (LOS) ranges from ' $A$ ' to ' $F$ ' (free flow to poorest/break down flow). The level of service from 'A' to ' $\mathrm{F}$ ' defines the both working conditions within a 
road traffic stream and that of road user's attentiveness. In level of service, the density of vehicular travel is measured. The time of delay for signalized and unsignalized intersection for LOS service ' $\mathrm{A}$ ' and ' $\mathrm{F}$ ' is less than $10 \mathrm{sec}$, greater than $80 \mathrm{sec}$ and less than $10 \mathrm{sec}$, greater than $50 \mathrm{sec}$ respectively (Mathew and Rao, 2006). An analysis method that offers for the determination of volume or level of service (LOS) at crossings is therefore a vital tool for engineers, operation staffs, and policy makers. Flow and distribution are the factors which affect the level of service of the intersections (Garber and Hoel, 2010). The Factors affecting LOS can include geometric and operating conditions, traffic characteristics and environmental conditions.

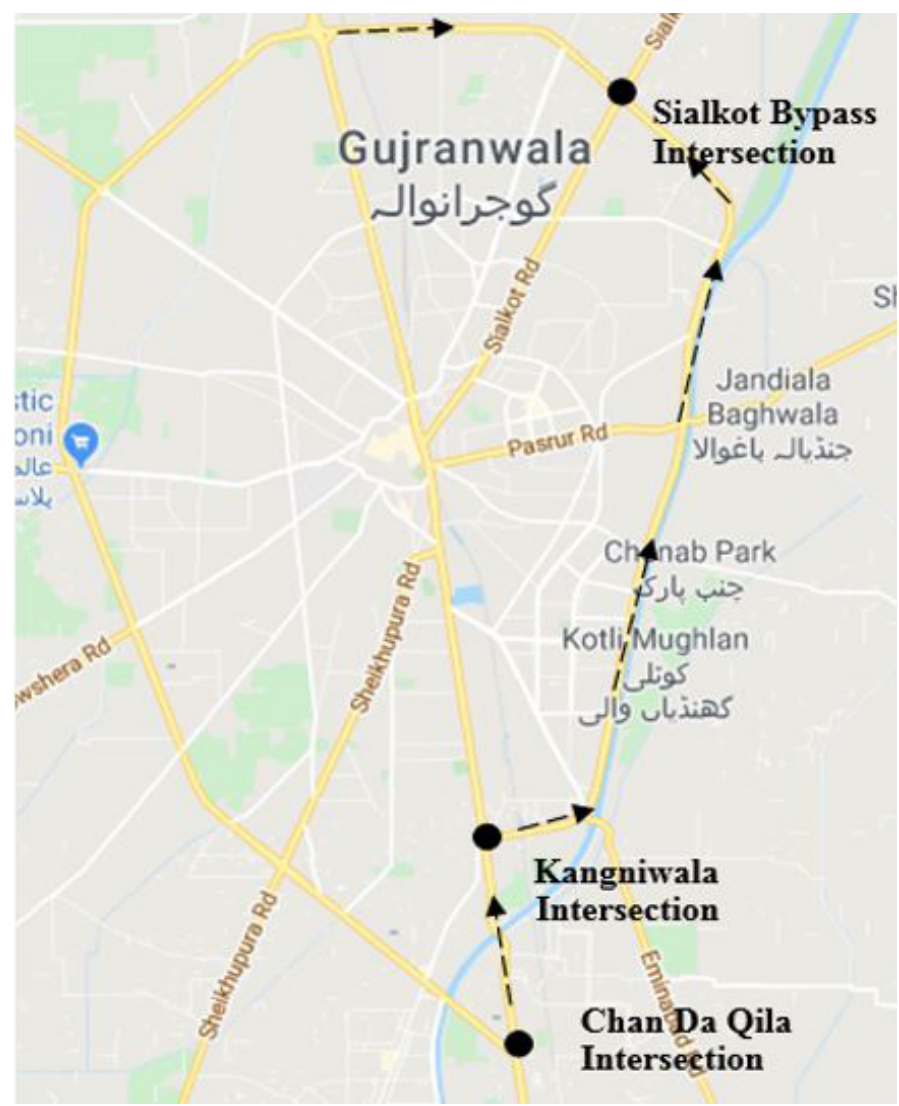

Figure 1: Study area.

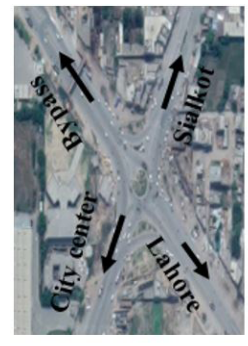

(a)

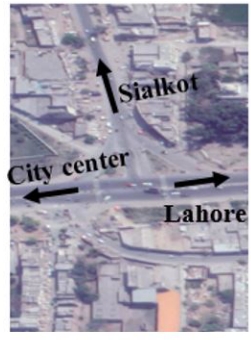

(b)

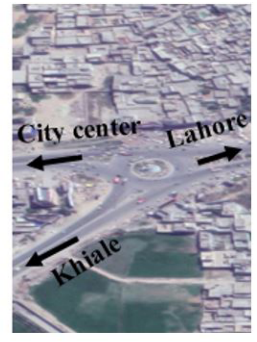

(c)
Figure 2: (a) Sialkot Bypass (b) Kangniwala, and (c) Chan Da Qila Intersection.
The LOS of the selected intersections is evaluated on the basis of delays and $\mathrm{V} / \mathrm{C}$ (volume capacity) ratios for existing and future possibilities considering peak hour traffic data. Volume capacity ratio measures the traffic congestion on roadway.

The purpose of this study is to evaluate the existing traffic conditions at the selected intersections and to recommend optimum solution using SIDRA software.

\section{Materials and Methods}

A rigorous qualitative and quantitative analysis is performed to achieve the goals. The quantitative field data collection is done that includes traffic count, topographic survey etc. In addition to that, qualitative data is also obtained from the data archives, reports and publications. Topography survey is conducted to find the existing conditions of roads. The tasks performed includes but not limited to collection of data about existing transport facilities and group discussions with local residents. Manual traffic count has been performed to assess the situation of the area. The vehicle volumes and its type are recorded at each intersection. Passenger Equivalency factor is used to transform traffic count into Passenger Car Unit (PCU) is given in Table 1 (Urban Unit, 2011).

Table 1: Passenger equivalency unit.

\begin{tabular}{|llllll} 
Vehicle type & Car & $\begin{array}{l}\text { Motor- } \\
\text { cycle }\end{array}$ & $\begin{array}{l}\text { Bi- } \\
\text { cycle }\end{array}$ & $\begin{array}{l}\text { Bus, } \\
\text { tractor }\end{array}$ & $\begin{array}{l}\text { Horse } \\
\text { cart, truck }\end{array}$ \\
Equivalency Factor & 1 & 0.5 & 0.2 & 3.5 & 4
\end{tabular}

From the measured traffic data, the higher number of traffic is selected as the peak traffic flow. The summary of the peak hours of selected intersection are given in Tables 2, 3 and 4. The trend of increase in traffic count is similar in all selected intersection at peak hour.

Table 2: PCUs at Sialkot bypass intersection.

$\begin{array}{llll}\text { Peak hour } & \text { 9am to 10am } & \text { 2pm to 3pm } & \text { 7pm to 8pm } \\ \text { PCUs } & 8157 & 10490 & 9661\end{array}$

Table 3: PCUs at Kanginwala bypass intersection.

$\begin{array}{llll}\text { Peak hour } & \text { 9am to10am } & \text { 3pm to } \mathbf{4 p m} & \mathbf{7 p m} \text { to } \mathbf{8 p m} \\ \text { PCUs } & 7460 & 5537 & 7149\end{array}$

Table 4: PCUs at Chan Da Qila intersection.

\begin{tabular}{|llll} 
Peak hour & 9am to 10am & 2pm to 3pm & 7pm to 8pm \\
PCUs & 4822 & 5222 & 5994
\end{tabular}

June 2021 | Volume 40 | Issue 1 | Page 3 
SIDRA is used to analyze the peak hour's data. SIDRA software is used for evaluating parameters of the intersections i.e. LOS, Degree of Saturation (DOS), Delay and V/C ratios. Then data is projected with the help of growth factor of Gujranwala city (3.5\% per year, Minallah et al., 2016). LOS of existing conditions of each intersection is also evaluated using the SIDRA. Interviews from the locals also helped in recommending solutions. Finally, LOS of each modified intersection is calculated using peak hour data. The results are compared with the existing and proposed conditions of the intersections.

\section{Results and Discussion}

This study uses SIDRA STANDARD Model for determining quality of traffic flow movement at the intersections. The existing situation performance is analyzed and sensitivity analysis for various parameters is carried out with various options for performance improvement.

\section{Sialkot bypass intersection}

The roundabout at Sialkot bypass intersection has three distinct traffic peak periods in weekday i.e. morning peak (9:00am to 10:00am); afternoon peak (02:00pm to $03: 00 \mathrm{pm})$ and evening peak $(07: 00 \mathrm{pm}$ to $8: 00 \mathrm{pm})$. The evening peak hour has highest traffic volume. It is used for the traffic analysis of existing and with modification condition. The growth factor of 3.5\% (Minallah et al., 2016) is used for the projection of traffic volumes of this intersection. The flow rates and performance of the Sialkot Bypass intersection for existing condition is shown in Figure 3 and are given in Table 5.

Table 5: Performance result of Sialkot Bypass Intersection for existing condition.

\begin{tabular}{lllll}
$\begin{array}{l}\text { Performance measure- } \\
\text { ment }\end{array}$ & \multicolumn{2}{l}{ Approach } \\
& South & East & North & West \\
Approach Flow(veh/h) & 3056 & 2532 & 2943 & 2299 \\
Degree of Saturation & 2.651 & 2.740 & 2.411 & 2.536 \\
LOS & $\mathrm{F}$ & $\mathrm{F}$ & $\mathrm{F}$ & $\mathrm{F}$ \\
Avg. control delay (Sec) & 2983 & 3145 & 2550 & 2334 \\
Avg. queue length (m) & 10636 & 8114 & 9002 & 7865
\end{tabular}

To determine the best suitable combination for modification, various options are tested. It is found that a modified form of the roundabout $(30 \mathrm{~m})$ is satisfying the desired results. The intersection is modified by providing dedicated right turns at each approach with the lane width increased from $3.4 \mathrm{~m}$ to $4 \mathrm{~m}$. The average LOS of all approaches is ' $\mathrm{B}$ '. The average Delay found to be 13.6 seconds per vehicle, which is very good. The average DOS of the intersection comes out to be 0.92 . The flow rates and performance of the Sialkot Bypass intersection for modified condition is given in Table 6 and shown in Figure 4.

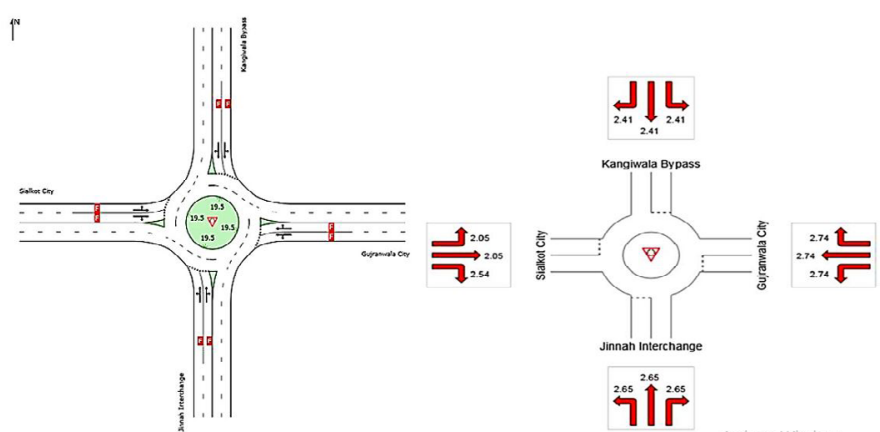

Figure 3: LOS and DOS of Sialkot Bypass Intersection for existing condition.

Table 6: Performance result of Sialkot Bypass Intersection for modified condition.

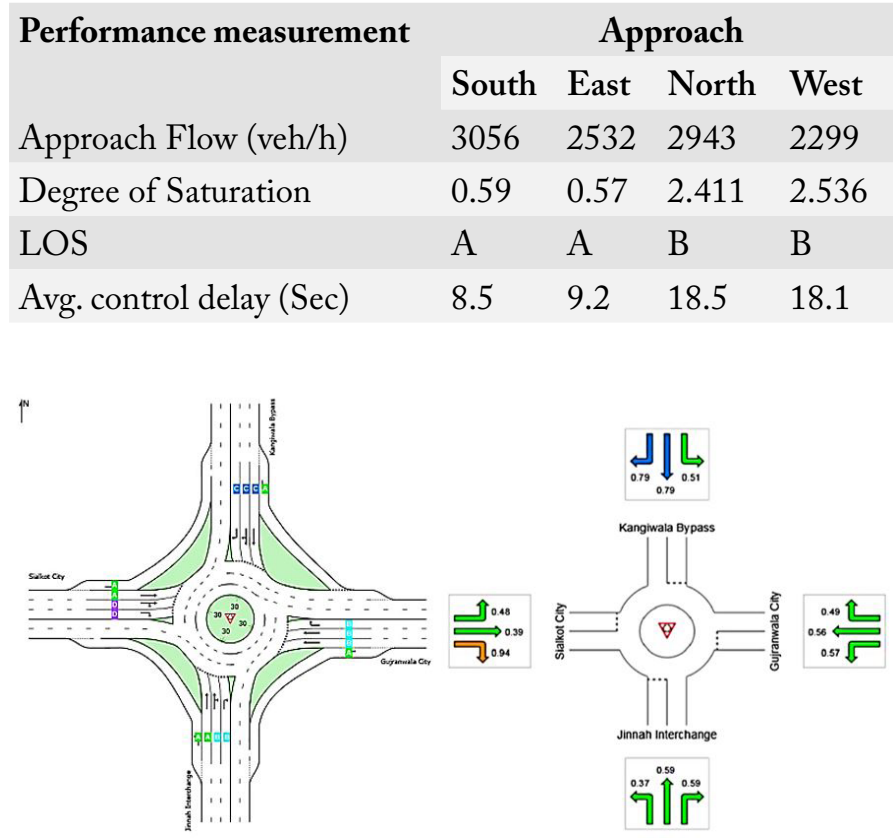

Figure 4: Modified LOS and DOS of Sialkot bypass intersection.

\section{Kangniwala bypass intersection}

The roundabout at Kangniwala bypass intersection has three distinct traffic peak periods in weekday i.e. morning peak (9:00am to 10:00am); afternoon peak (03:00 pm to 04:00 pm) and evening peak (07:00pm to 08:00pm). The morning peak hour has highest traffic volume. It is used for the traffic analysis of existing and with modification condition. The growth factor of $3.5 \%$ is used for the projection of traffic volumes 
of this intersection. The flow rates and performance of the Kangniwala Bypass intersection for existing condition is shown in Figure 5 and are given in Table 7.

Table 7: Performance result of Kangniwala Bypass Intersection for existing condition.

\begin{tabular}{llll} 
Performance measurement & \multicolumn{3}{l}{ Approach } \\
& North & East & West \\
Approach Flow(veh/h) & 1325 & 1123 & 1258 \\
Degree of Saturation & 1.9 & 1.6 & 2.67 \\
LOS & F & F & F \\
Avg. control delay (Sec) & 325 & 362 & 248 \\
Avg. queue length (m) & 425 & 335 & 318
\end{tabular}

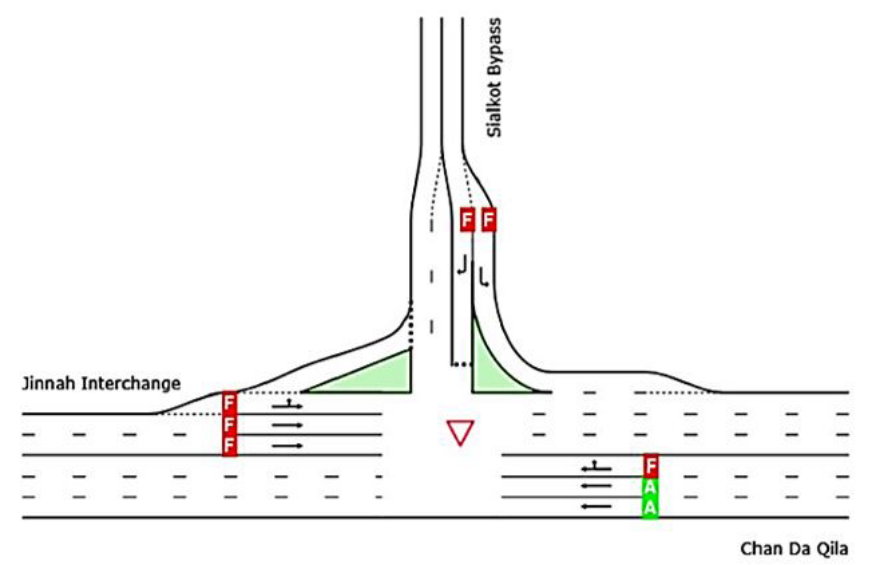

Figure 5: LOS of Kangniwala Bypass Intersection for existing condition.

To determine the best suitable combination for modification, various options are tested. It is found that a modified form of the roundabout is satisfying the desired results. The intersection is modified by providing dedicated right turns at each approach with the lane width increased from $3.4 \mathrm{~m}$ to $4 \mathrm{~m}$. In addition to that, provision of fixed time isolated signals at each approach with a cycle time of 40 seconds is also included. The average LOS of all approaches is ' $\mathrm{B}$ '. The average Delay found to be 14.9 seconds per vehicle which is very good. The average DOS of the intersection comes out to be 0.86 . The modified intersection is also analyzed at the future projections and its results are satisfactory for the next 10 years. The flow rates and performance of the Kangniwala Bypass intersection for modified condition is given in Table 8 and shown in Figure 6.

\section{Chan Da Qila intersection}

The roundabout at Chan Da Qila intersection intersection has three distinct traffic peak periods in weekday i.e. morning peak (9:00am to 10:00am); afternoon peak (02:00 pm to 03:00 pm) and evening peak (07:00pm to 08:00pm). The morning peak hour has highest traffic volume. It is used for the traffic analysis of existing and with modification condition. The growth factor of $3.5 \%$ is used for the projection of traffic volumes of this intersection. The flow rates and performance of the Chan Da Qila intersection for existing condition is shown in Figure 7 and are given in Table 9.

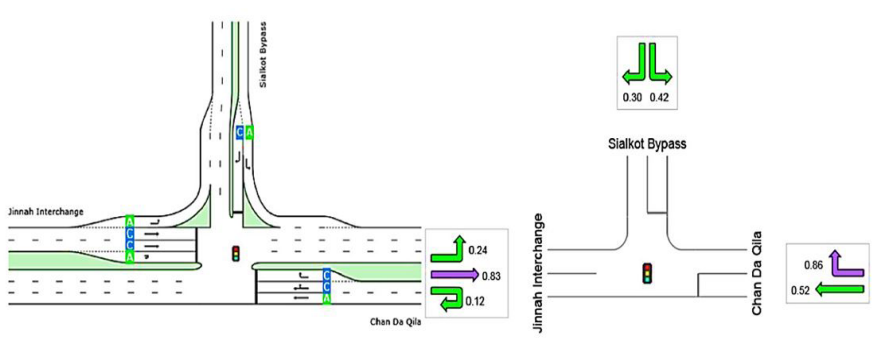

Figure 6: Modified LOS and DOS of Kangniwala Bypass Intersection.

Table 8: Performance result of Kangniwala Bypass Intersection for modified condition.

\begin{tabular}{llll} 
Performance measurement & \multicolumn{3}{c}{ Approach } \\
& North & East & West \\
Approach Flow(veh/h) & 1325 & 1123 & 1258 \\
Degree of Saturation & 0.42 & 0.86 & 0.83 \\
LOS & A & B & B \\
Avg. control delay (Sec) & 8.1 & 19.3 & 14.7 \\
Avg queue length $(\mathrm{m})$ & 45 & 95 & 56
\end{tabular}

Table 9: Performance result of Chan Da Qila Intersection for existing condition.

\begin{tabular}{llll} 
Performance measurement & \multicolumn{3}{l}{ Approach } \\
& South & East & West \\
Approach Flow(veh/h) & 1524 & 3217 & 1981 \\
Degree of Saturation & 1.8 & 1.6 & 1.8 \\
LOS & F & F & F \\
Avg. control delay (Sec) & 1190 & 1128 & 513 \\
Avg. queue length (m) & 3464 & 7376 & 2525
\end{tabular}

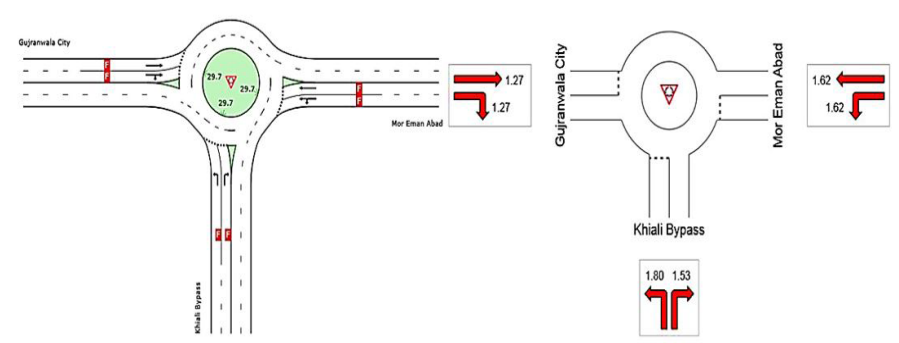

Figure 7: LOS and DOS of Chan Da Qila Intersection for existing condition. 
To determine the best suitable combination for modification, various options are tested. It is found that a modified form of the roundabout is satisfying the desired results. The intersection is modified by providing dedicated right turns at each approach with the lane width increased from $3.4 \mathrm{~m}$ to $4 \mathrm{~m}$ along with increase in exit lane. The average LOS of all approaches is ' $\mathrm{B}$ '. The average Delay found to be 12.2 seconds per vehicle which is very good. The average DOS of the intersection comes out to be 0.889 . The modified intersection is also analyzed at the future projections and its results are not satisfactory after 5 years. Grade separated interchange is recommended for long term solution. The flow rates and performance of the Chan $\mathrm{Da}$ Qila intersection for modified condition is given in Table 10 and shown in Figure 8.

Table 10: Performance result of Chan Da Qila Intersection for modified condition.

\begin{tabular}{llll} 
Performance measurement & \multicolumn{3}{c}{ Approach } \\
Approach Flow $(\mathrm{veh} / \mathrm{h})$ & South & East & West \\
Degree of Saturation & 1524 & 3217 & 1981 \\
LOS & 0.89 & 0.80 & 0.525 \\
Avg. control delay $(\mathrm{Sec})$ & $\mathrm{C}$ & $\mathrm{A}$ & $\mathrm{B}$ \\
Avg. queue length $(\mathrm{m})$ & 29.4 & 7.4 & 6.6 \\
& 126.5 & 103.4 & \\
& & &
\end{tabular}

Figure 8: Modified LOS and DOS of Chan Da Qila intersection.

\section{Conclusions and Recommendations}

The following conclusion can be drawn from the study:

1. It is concluded that by implementing good traffic management plans with proper signal coordination and by increasing the number of lanes; travel delays can be minimized.

2. The analysis of existing condition of Chan $\mathrm{Da}$ Qila, Kangniwala and Sialkot Bypass intersections have revealed that LOS of each intersection is very poor due to high delays on approaches.

3. Proposed modification for Sialkot Bypass and Chan Da Qila intersection includes dedicated right turns at each approach along with lane width increased from $3.4 \mathrm{~m}$ to $4 \mathrm{~m}$. The island diameter of roundabout is increased to $30 \mathrm{~m}$. In addition to that, increase in exit and entry lanes is also proposed.

4. Kangniwala Bypass modification includes provision of fixed time isolated signals at each approach with a cycle time of 40 seconds. Furthermore, increase in number of entry and exit lanes is proposed.

5. The modified intersections are also analyzed at the future projections and their results are satisfactory to 5 years but afterwards performance is not satisfactory. Permanent solution can be provided in the form of grade separated interchanges.

6. The proposed modification of intersection shows improvement of LOS. Channelization and dedicated left and right turns have helped to improve the LOS and reduce the delays.

\section{Novelty Statement}

Techniques to improve level of service and degree of saturation of roads are proposed for selected intersections of Gujranwala City, Pakistan.

\section{Author's Contribution}

Khawaja Adeel Tariq has done data analysis, quality assurance and drafted the article. Hadhi Hassan Khan carried out technical review of the article and literature review. Shuja Zaib Afghan has supported the principle author in data collection and analysis. Arslan Raza supported the authors in data collection.

\section{Conflict of interest}

The authors have declared no conflict of interest.

\section{References}

Arshi, A., W.K. Alhajyaseen, H. Nakamura and X. Zhag. 2018. A comparative study on the operational performance of fourleg intersections by control type. Transport. Res. A Policy Pract., 118: 52-67. https://doi. org/10.1016/j.tra.2018.08.039

Candappa, N., D. Logan, N.N. Van and B.F. Corben. 2015. An exploration of alternative intersection designs in the context of safe system. Accid. Anal. Prev., 74: 314-323. https:// doi.org/10.1016/j.aap.2014.07.030 
Garber, N.J. and L.A. Hoel. 2010. Traffic and highway engineering. $4^{\text {th }}$ Edition, Cengage Learning, USA.

Hamid, Z., 2017. Impact of high-performance work systems on export-oriented smes performance: the mediating role of human capital development. South Asian J. Manage., 11(2): 142-163. https://doi.org/10.21002/ seam.v11i2.8524

Mathew, T.V. and K.K. Rao. 2006. Introduction to transportation engineering. NPTEL web course, 2006.

Martin, T., T. Thoresen and U. Ai. 2017. Estimating levels of service (LOS) for freight on rural roads. Road Transport Res., 26(1): 48-63.

Minallah, M.N., A. Ghaffar, M. Rafique and M. Mohsin. 2016. Urban growth and socioeconomic development in Gujranwala, Pakistan: A geographical analysis. Pak. J. Sci., 68(2): 176-183.

Neuman, T.R., Pfefer and K.L. Slack. 2003. A guide for addressing unsignalized intersection collisions. NCHRP report 500, National cooperative highway research, transportation research board of the national academies, Washington D.C.

Pakistan Bureau of Statistics. 2017. Province wise provisional result of census.

Pilko, H., N. Bozic and N. Subic. 2011. Analysis of roundabout capacities in the city of Zagreb using Swiss method SN 640 024. Conference proceedings Transport, Maritime and Logistics Science, $14^{\text {th }}$ ICTS, 2011.

Punjab Development Statistics. 2014. Bureau of Statistics, Government of the Punjab.

Sabra, Z., C.E. Wallace and F. Lin. 2000. Traffic analysis software tools. Transportation research board/ National Research Council.

Salini, S. and R. Ashalatha. 2018. Analysis of traffic characteristics of urban roads under the influence of roadside frictions. Case Stud. Transport Policy, 8(1): 94-100. https://doi. org/10.1016/j.cstp.2018.06.008

The Urban Unit, 2011. Punjab Geometric Design Manual.

Transport Planning Unit, 2013. Proposal of development of pedestrian facilities in Gujranwala City. 